\title{
Outcomes after Acute Peritoneal Dialysis for Critical Cardiorenal Syndrome Type 1
}

\author{
Watanyu Parapiboon Tanit Kingjun Laddaporn Wongluechai \\ Waraporn Leawnoraset \\ Department of Medicine, Maharat Nakhon Ratchasima Hospital, Nakhonratchasima, Thailand
}

\section{Keywords}

Cardiorenal syndrome type 1 - Acute kidney injury ·

Peritoneal dialysis · Ultrafiltration · Mortality

\begin{abstract}
Introduction: The aim of the study was to demonstrate the outcomes of peritoneal dialysis (PD) in critically ill cardiorenal syndrome type 1 (CRS1). Methods: A cohort of 147 patients with CRS1 who received PD from 2011 to 2019 in a referral hospital in Thailand was analyzed. The primary outcome was 30-day in-hospital mortality. Ultrafiltration and net fluid balance among survivors and nonsurvivors in the first 5 PD sessions were compared. Results: The 30-day mortality rate was $73.4 \%$. Most patients were critically ill CRS1 (all patients had a respiratory failure of which $68 \%$ had cardiogenic shock). Blood urea nitrogen and creatinine at the commencement of PD were 60.1 and $4.05 \mathrm{mg} / \mathrm{dL}$. In multivariable analysis, increasing age, unstable hemodynamics, and positive fluid balance in the first 5 PD sessions were associated with the risk of in-hospital mortality. The change of fluid balance per day during the first 5 dialysis days was significantly different among survivor and nonsurvivor groups (-353 vs. $175 \mathrm{~mL}$ per day, $p=0.01)$. Conclusions: $P D$ is a viable dialysis option in CRS1, especially in a resource-limited setting. PD can save up to $27 \%$ of lives among patients with critically ill CRS1.

(C) 2021 The Author(s)

Published by S. Karger AG, Basel
\end{abstract}

\section{Introduction}

Cardiorenal syndrome type 1 (CRS1) is an acute worsening of cardiac function mainly from acute coronary syndrome (ACS) with cardiogenic shock or acute heart failure leading to acute kidney injury (AKI) $[1,2]$. CRS1 is common, with approximately $13-33 \%$ of patients suffering worldwide with acute heart failure along with hospitalization [3, 4]. Management of CRS1 typically focuses on the correctable cause of heart failure, optimal fluid management to maintain adequate renal perfusion, and avoiding congestion of the lung and mechanical circulatory support. If fluid overload occurs, using a loop diuretic to promote urine output is the cornerstone of pharmacological treatment. Ultrafiltration (UF) for fluid removal in a patient without significant renal impairment can be applied in CRS1. However, mortality in UF therapy is not significantly different from using a loop diuretic and UF therapy may be associated with adverse renal outcomes [5-7]. When significant renal impairment occurs, renal replacement therapy (RRT) is needed for either fluid or solute removal. Continuous RRT (CRRT) has been commonly used in a resource-rich setting. Nevertheless, the mortality rate of CRS1 with CRRT is still high $[8,9]$. Another option for RRT in CRS1 is peritoneal dialysis (PD). PD is one of the acceptable dialysis modalities in AKI [10]. PD has an advantage in CRS1 over extracorporeal dialysis as PD requires less infrastructure and ma-
(C) 2021 The Author(s)

Published by S. Karger AG, Basel

This is an Open Access article licensed under the Creative Commons Attribution-NonCommercial-4.0 International License (CC BY-NC) (http://www.karger.com/Services/OpenAccessLicense), applicable to the online version of the article only. Usage and distribution for commercial purposes requires written permission.
Correspondence to:

Watanyu Parapiboon, watanyu.kr@cpird.in.th 
chines, including dialysis staff. Therefore, PD is suitable for a limited-resource setting or even a rich resource country, especially due to the shortage of dialysis resources during the pandemic [11]. Moreover, PD is gentler and causes less hemodynamic disturbance than extracorporeal dialysis. Hypotension and arrhythmia usually occur especially during extracorporeal dialysis in CRS1 due to acute impaired cardiac function. This can lead to the early termination of dialysis. Another benefit of PD is a low risk of bleeding because PD does not require an anticoagulant. Previous experience of PD for control of volume overload in refractory congestive heart failure has shown acceptable outcomes [12-14]. Interestingly, PD has shown more benefit for fluid balance control and preserving renal function than UF therapy in CRS1 from a small randomized study [15]. For all of these reasons, PD should be one of the attractive dialysis modalities in CRS1 especially in critically ill or unstable hemodynamic cases. There were explicit data of using PD in cardiorenal syndrome type 2 for fluid control in chronic and or refractory congestive heart failure $[13,16]$. Nevertheless, the data on outcomes and feasibility of using PD in CRS1, which had acute heart failure and significant renal impairment, are scant and more are urgently needed. We aim to report the 30-day in-hospital mortality rate of patients with CRS1 from ACS with AKI stage 3 who were treated with PD in a tertiary referral hospital in Thailand. Second, we aim to demonstrate the association of total fluid balance and fluid removal from PD in the first 5 dialysis days with mortality.

\section{Materials and Methods}

\section{Study Population}

Patients with CRS1 from ACS who were receiving PD due to AKI from 2011 to 2019 in our hospital were included. Patients with advanced chronic kidney disease (eGFR $<30 \mathrm{~mL} / \mathrm{min} / 1.73 \mathrm{~m}^{2}$ ) or end-stage renal disease with regular long-term dialysis, previous midline lower abdominal surgery or obesity $\left(B M I \geq 35 \mathrm{~kg} / \mathrm{m}^{2}\right)$ were excluded. Patients who had other combined dialysis modalities (CRRT or prolonged intermittent hemodialysis) with PD were also excluded. This study was approved by the Maharat Nakhorn Hospital Institution Review Board, with Approval number 065/2020.

\section{ACS and Percutaneous Coronary Intervention}

ACS was diagnosed by a cardiologist, according to clinical manifestation with suspected angina pain, specific EKG patterns for ischemia, either ST-segment elevation or depression at least 2 leads and cardiac troponin I level above the upper normal limit for 2 consecutive time points. A fast-track protocol was activated in STEMI to shorten door-to-needle time or door-to-balloon time with thrombolytic therapy with streptokinase or percutaneous coronary intervention (PCI). In non-ST-elevation myocardial infarction, PCI was performed in selected cases usually with cardiogenic shock or intractable chest discomfort. PCI was performed by an intervention cardiologist via a femoral or radial artery approach. The use of a drug elution stent, bared metal stent or plainold balloon angioplasty with or without a glycoprotein $2 \mathrm{~b}-3 \mathrm{a}$ receptor antagonist added depended on the coronary lesion. Standard care for ACS patients was provided, including oxygen therapy, ventilation support, dual antiplatelet, and low molecular weight heparin. An intra-aortic balloon pump (IABP) with inotropic drugs was used in patients with unstable hemodynamic.

\section{AKI and Initiation of Dialysis}

AKI from ACS was defined as creatinine rising according to AKIN criteria [17] after admission within $48 \mathrm{~h}$ from ACS. A nephrologist was consulted and was involved in fluid management, typically after AKI stage 2 had occurred. Using optimal fluids to maintain hemodynamics and organ perfusion but avoiding fluid overload is the principle of fluid management. Lung congestion commonly occurred in CRS1, and this was typically managed with continuous intravenous furosemide therapy. Dosage of furosemide was titrated and adjusted to a maximum of $1 \mathrm{~g}$ per day with the aim to promote urine output. Blood tests for biochemistry and urine were monitored closely. PD was initiated by nephrologist judgment based on using the conventional indicators for starting dialysis, that is, volume overload, hyperkalemia, metabolic acidosis, and uremia.

\section{PD Catheter Insertion and Prescription}

Flexible-coiled PD insertion (Quinton percutaneous insertion kit) was performed by a nephrologist using a percutaneous bedside technique without imaging guidance. A low midline or paramedian incision was used. Systemic cefazolin $1 \mathrm{~g}$ was given $1 \mathrm{~h}$ before $\mathrm{PD}$ catheter insertion except for patients who were already receiving other broad-spectrum antibiotics. Manual PD (gravity-driven) with a single bag (open system) was started immediately after PD catheter insertion with 1.5 L of PD fluid (General Hospital Products Public Co., Ltd, Thailand). The fluid comprised Na 132 $\mathrm{mEq} / \mathrm{L}, \mathrm{K} 0 \mathrm{mEq} / \mathrm{L}, \mathrm{Mg} 0.5 \mathrm{mEq} / \mathrm{L}$, Ca $2.5 \mathrm{mEq} / \mathrm{L}$, lactate 35 $\mathrm{mEq} / \mathrm{L}$, and $1.5 \%$ of glucose. Then, $4.25 \%$ of glucose PD fluid was used to increase UF in patients with significant volume overload. A 1.5 L fill volume with 1 - or 2-h cycles (36 or $18 \mathrm{~L}$ of PD volume per day) was used for the first 2-3 days, and then this was adjusted to 3-6-h cycles depending on volume status and metabolic profiles. UF and blood samples were monitored closely. PD fluid with a differentiated cell count was also routinely sent to the laboratory for daily surveillance of $\mathrm{PD}$ peritonitis. $\mathrm{PD}$ peritonitis is defined as white cell count $>100 / \mu \mathrm{L}$ with at least $50 \%$ polymorphonuclear cells in the peritoneal fluid according to the International Society of Peritoneal Dialysis guidelines [18].

\section{Outcome}

The primary outcome was a 30 -day in-hospital mortality rate. The secondary outcome included a dialysis dependence rate at 90 days, PD-related complications, and the risk of death. Cumulative fluid balance (total fluid intake minus total output including UF from PD and urine output) and UF from PD during the first 5 dialysis days among the survival and the nonsurvival groups were compared. 
Table 1. Baseline characteristics data $(n=147)$

\begin{tabular}{|c|c|c|c|c|}
\hline Characteristics & Total $(n=147)$ & Dead $(n=108)$ & Alive $(n=39)$ & $p$ value* \\
\hline Age, mean (SD) & $68.42 \pm 12.55$ & $69.73 \pm 12.48$ & $64.79 \pm 12.17$ & 0.035 \\
\hline Male, $n(\%)$ & $83(56.5)$ & $57(52.8)$ & $26(66.7)$ & 0.134 \\
\hline BW, kg, mean (SD) & $57.30 \pm 10.28$ & $57.40 \pm 10.47$ & $57.24 \pm 10.38$ & 0.963 \\
\hline $\mathrm{DM}, n(\%)$ & $66(44.9)$ & $52(48.1)$ & $14(35.9)$ & 0.187 \\
\hline $\mathrm{HT}, n(\%)$ & $83(56.5)$ & $68(63.0)$ & $15(38.5)$ & 0.008 \\
\hline CKD (eGFR < 60), $n(\%)$ & $17(11.6)$ & $15(13.9)$ & $2(5.1)$ & 0.241 \\
\hline Unstable hemodynamic, $n(\%)$ & $101(68.7)$ & $81(75.0)$ & $20(51.3)$ & 0.006 \\
\hline Urine output, $\mathrm{mL} / \mathrm{kg} / \mathrm{h}$, median (IQR) & $0.12(0-0.51)$ & $0.12(0-0.34)$ & $0.11(0-0.64)$ & 0.353 \\
\hline Fluid balance before PD, mL, median (IQR) & $2,100(1,100-4,200)$ & $2,100(1,175-4,125)$ & $1,900(830-5,000)$ & 0.494 \\
\hline \multicolumn{5}{|l|}{ Indication for dialysis, $n(\%)$} \\
\hline Volume overload & $102(69.4)$ & $77(71.3)$ & $25(64.1)$ & 0.403 \\
\hline Hyperkalemia & $22(15.0)$ & $15(13.9)$ & $7(17.9)$ & 0.542 \\
\hline NSTEMI, $n(\%)$ & $45(30.6)$ & $32(29.6)$ & $13(33.3)$ & 0.808 \\
\hline GRACE score (for NSTEMI), median (IQR), $n(\%)$ & $174(28-189)$ & $176(24-193)$ & $170.5(127-181)$ & 0.588 \\
\hline IABP, $n(\%)$ & $55(37.4)$ & $44(40.7)$ & $11(28.2)$ & 0.166 \\
\hline PCI, $n(\%)$ & $96(65.3)$ & $70(64.8)$ & $26(66.7)$ & 0.835 \\
\hline \multicolumn{5}{|l|}{ Coronary artery lesion $(n=96$, with PCI), $n(\%)$} \\
\hline LM & $12(12.5)$ & $9(12.9)$ & $3(11.5)$ & 0.284 \\
\hline LAD & $41(42.7)$ & $33(47.1)$ & $8(30.8)$ & \\
\hline RCA & $25(26.0)$ & $15(21.4)$ & $10(38.5)$ & \\
\hline DVD & $14(14.6)$ & $9(12.9)$ & $5(19.2)$ & \\
\hline TVD & $4(4.2)$ & $4(5.7)$ & $0(0.0)$ & \\
\hline \multicolumn{5}{|l|}{$\mathrm{EF}(n=95), n(\%)$} \\
\hline Good $(>60)$ & $14(14.7)$ & $7(11.5)$ & $7(20.6)$ & 0.043 \\
\hline
\end{tabular}

Data are presented as $n(\%)$, mean $\pm \mathrm{SD}$, or median (IQR). BW, body weight; IABP, intra-aortic balloon pump; PCI, primary coronary intervention; EF, ejection fraction; LM, left main; LAD, left anterior descending; RCA, right coronary artery; DVD, double vessel disease; TVD, triple vessel disease; SD, standard deviation; IQR, interquartile range; CKD, chronic kidney disease. * Comparison between death group and survive group; Student's t test, Mann-Whitney U test, $\chi^{2}$ test, and Fisher's exact test.

\section{Statistical Analysis}

Descriptive data were expressed as mean and standard deviation for normal distribution and median and interquartile range for skewed distribution. Descriptive statistics were compared for the survivor and nonsurvival groups using a $\chi^{2}$ test for categorical variables and Student's $t$ test or Wilcoxon rank-sum test for continuous variables. The change of total fluid balance and UF from PD in the first 5 dialysis sessions was compared between survival and nonsurvival groups using linear mixed-effect models. Logistic regression with univariable and multivariable analyses was used to determine the risk of death. Selected covariates with $p<0.05$ in the univariate model were input into the multivariate analysis. All statistical calculations were performed using the STATA software release 14 (StataCorp LP, College Station, TX, USA).

\section{Results}

During the study period, 250 patients were diagnosed with CRS 1 and received RRT, of whom 147 participants were included (103 were excluded, 21 were chronic kidney disease stages 4 and 5 , and 82 received other dialysis treatment (intermittent hemodialysis, prolonged intermittent RRT) or CRRT, or combined extracorporeal dialysis with PD). The baseline characteristics of the study population are shown in Table 1 . The mean age was 68 years and around half of the patients had underlying diseases, including hypertension and diabetes. All patients had a respiratory failure which required mechanical ven- 
Table 2. Biochemical parameters at dialysis initiation

\begin{tabular}{lcccc}
\hline Characteristics & Total $(n=147)$ & Dead $(n=108)$ & Alive $(n=39)$ & $p$ value* \\
\hline $\mathrm{HB}$ & $10.3(9.1-11.7)$ & $10.45(9.23-11.78)$ & $10.1(8.7-11.6)$ & 0.398 \\
$\mathrm{BUN}$ & $60.1(43.1-87)$ & $57.4(41.45-84.05)$ & $72.4(50.8-96.5)$ & 0.115 \\
$\mathrm{Cr}$ & $4.05(2.98-5.75)$ & $3.95(3.03-5.41)$ & $4.39(2.69-6.96)$ & 0.434 \\
$\mathrm{Na}$ & $136.8(131.3-5.15)$ & $137.15(131.93-142.08)$ & $135.8(128.2-139.1)$ & 0.027 \\
$\mathrm{~K}$ & $4.43(3.8-5.15)$ & $4.33(3.69-5.03)$ & $4.72(4.08-5.33)$ & 0.177 \\
$\mathrm{Cl}$ & $99.2(94.7-102.8)$ & $99.25(95.7-102.68)$ & $99.1(92.1-103.4)$ & 0.458 \\
$\mathrm{HCO}_{3}$ & $16.85(11.25-21.23)$ & $16.85(11.03-21.18)$ & $17.3(12.95-21.5)$ & 0.298 \\
\hline
\end{tabular}

Data are presented as median (IQR). BUN, blood urea nitrogen; $\mathrm{Cr}$, creatinine, $\mathrm{Na}$, sodium; K, potassium; CI, confidence interval; IQR, interquartile range. * Mann-Whitney $\mathrm{U}$ test for comparison between death group and survive group.

tilator support. Most of the patients (68\%) were in cardiogenic shock mainly from acute-STEMI MI and an IABP was used to support around one-third. For fluid management, the participants had oliguria before starting $\mathrm{PD}$ (median urine output $0.12 \mathrm{~mL} / \mathrm{kg} / \mathrm{h}$ for $6 \mathrm{~h}$ ) and median positive fluid balance for $2,100 \mathrm{~mL}$ before initiating dialysis. Therefore, the main indication for initiation of dialysis was volume overload (69\%). Mean biochemistry data at the initiation of dialysis were $\mathrm{BUN}$ and $\mathrm{Cr}$ around 60.1 $\mathrm{mg} / \mathrm{dL}$ and $4.05 \mathrm{mg} / \mathrm{dL}, \mathrm{K} 4.43 \mathrm{mmol} / \mathrm{L}$, and $\mathrm{HCO}_{3} 16.8$ $\mathrm{mmol} / \mathrm{L}$ as in Table 2 .

Median PD fluid volume was $36 \mathrm{~L}$ per day $(1.5 \mathrm{~L}$ per bag with 24 manual exchanges) in the first 2 PD sessions which were decreased to 9-18 L of PD fluid per day in later PD sessions. PD fluid with $1.5 \%$ dextrose was mainly used in $2 / 3$ of the total exchanges, whereas $1 / 3$ of the exchanges used $4.5 \%$ dextrose PD fluid (Table 3). Using these prescriptions, PD can archive a median UF around $1,100-1,200 \mathrm{~mL}$ per day.

On the fifth day of PD sessions, the net positive fluid balance in the survival group was lower than in the nonsurvival group $(1,743$ vs. $3,604, p=0.18)$ as detail in online suppl. files; for all online suppl. material, see www. karger.com/doi/10.1159/000517362. There was a negative mean change of fluid balance per day in the survival group ( $-353 \mathrm{~mL}$ per day), whereas a positive mean change of fluid balance per day in the nonsurvival group $(175 \mathrm{~mL}$ per day) as shown in Figure 1. Cumulative UF in the first $5 \mathrm{PD}$ sessions in the survival group was higher than in the nonsurvival group $(7,735 \mathrm{~mL}$ vs. $5,797 \mathrm{~mL}, p=0.07)$, as shown in Figure 2.

The overall 30-day in-hospital mortality rate was $73.5 \%$ (108 out of 147). Multivariate analysis showed that increasing age (OR 1.66, 95\% CI $1.17-2.36$ for 10 years increase), unstable hemodynamics (OR 3.3, 95\% CI 1.39-
7.81), and positive total fluid balance over the first 5 days of PD (OR 2.5, 95\% CI 1.03-6.06) were factors for an increased risk of death. Neither fluid balance before starting $\mathrm{PD}$, biochemistry at initiating dialysis nor dosage in the first 2 PD sessions were associated with mortality (Table 4).

The complications of PD were PD peritonitis (6.1\%), PD catheter malposition (11.8\%, 4.8\% needed revision and $7 \%$ needed no revision of the PD catheter). There were $6.1 \%$ (9 out of 147) of patients switched to CRRT due to PD technique failure (Table 5). This was mainly from PD catheter malfunction. The 90-day dialysis dependence rate among the survival group was $6.1 \%$ (2 out of 33).

\section{Discussion}

This study found a high-mortality rate in critically ill CRS1 patients who perform PD as renal support. Among the surviving patients, most of them had a renal recovery. The patients with CRS1 mainly from STEMI with cardiogenic shock, who required RRT because of significant renal impairment, had a poor prognosis. On the other hand, this study demonstrated the feasibility of PD for hemodynamic tolerability in these critically ill patients, where extracorporeal dialysis might not be tolerated or might not be available. Finally, PD can save up to $27 \%$ of lives in patients with severe CRS1. Patients with CRS1 in our study had worse outcomes than any other studies. All of the patients had respiratory failure, mainly unstable hemodynamics from STEMI with cardiogenic shock or non-ST-elevation myocardial infarction with a high GRACE score. Unsurprisingly, the mortality rate was higher than those in the previous studies $[9,19-22]$. The 


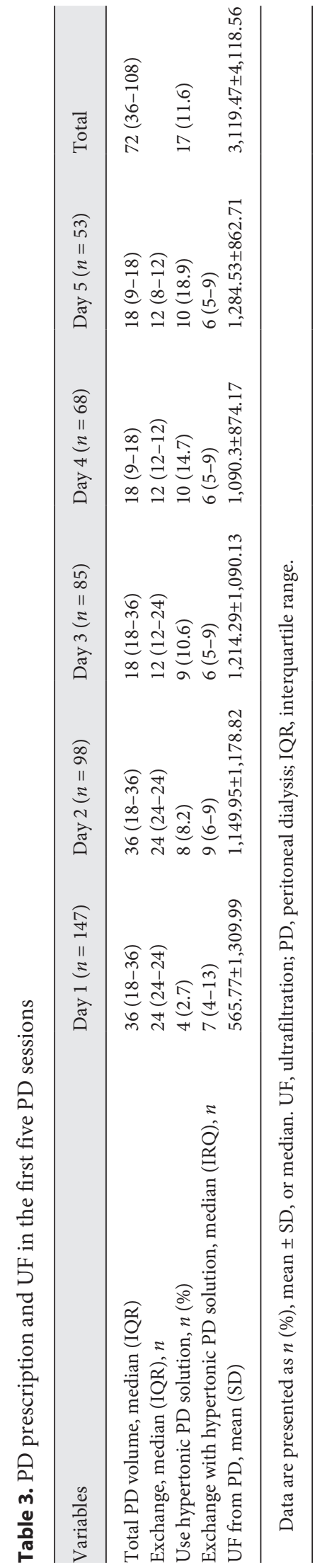

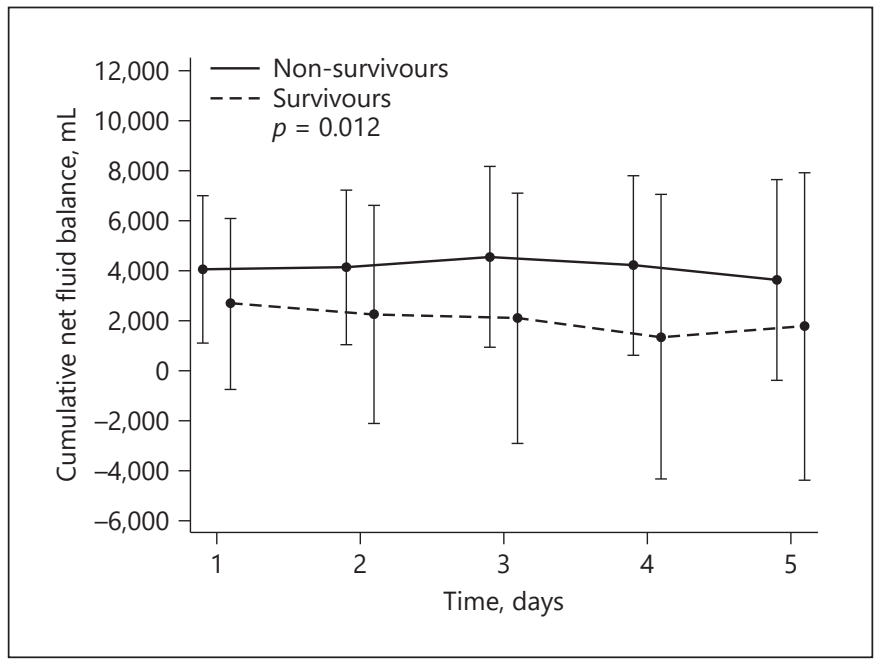

Fig. 1. Cumulative fluid balance between survivor and nonsurvival.

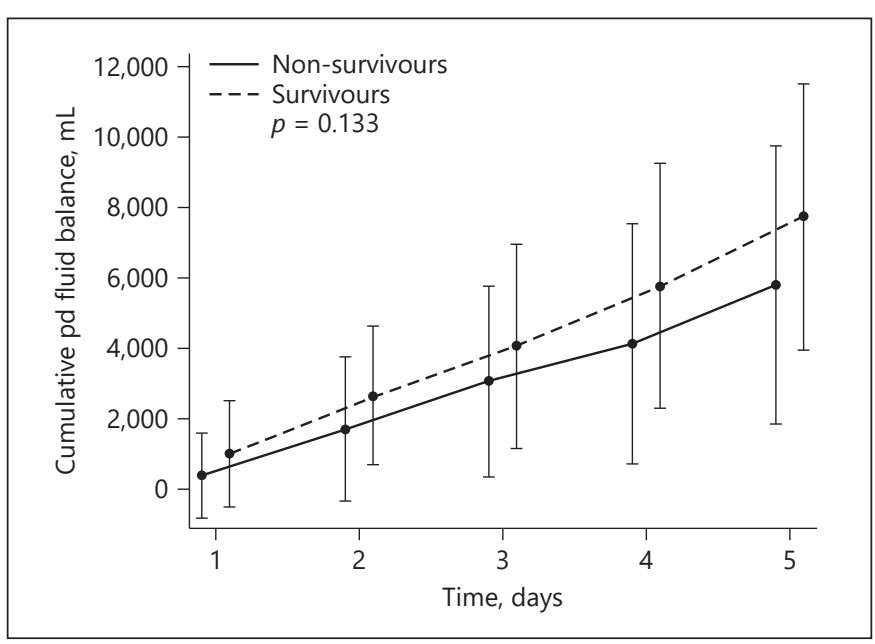

Fig. 2. UF from PD between survivor and nonsurvival. PD, peritoneal dialysis; UF, ultrafiltration.

mortality rate of the UF study to remove fluid in CRS1 patients was around $10-17 \%$ at 90 days, but all of the patients had stable blood pressure and normal to mild renal insufficiency (mean Cr around 1.5-2.0 mg/dL at the start of UF). Studies using CRRT in CRS1 with significant AKI found a high-mortality rate of around $43-62 \%[8,20]$. One study report from the USA suggested that a subgroup analysis of patients with CRS1 with AKI stage 3 who were $>70$ years old had $100 \%$ mortality [8]. Therefore, this study raises the challenging question of efficiency as to whether initiating CRRT support or palliative care in critical CRS1 patients with AKI stage 3 is 
Table 4. Multiple logistic regression analysis for factors associated with 30-day in-hospital mortality

\begin{tabular}{|c|c|c|c|c|c|c|}
\hline STEMI versus NSTEMI & 1.19 & $(0.54-2.60)$ & 0.667 & & & \\
\hline \multicolumn{7}{|l|}{ EF (good as reference) } \\
\hline Fair & 1.22 & $(0.36-4.14)$ & 0.747 & & & \\
\hline $\mathrm{BUN}>60 \mathrm{mg} / \mathrm{dL}$ & 0.48 & $(0.23-1.03)$ & 0.059 & & & \\
\hline $\mathrm{Cr}>4 \mathrm{mg} / \mathrm{dL}$ & 0.58 & $(0.28-1.23)$ & 0.154 & & & \\
\hline PD dosage (day $1+$ day 2$) \leq 40 \mathrm{~L}$ & 2.43 & $(1.13-5.23)$ & 0.023 & 1.82 & $(0.76-4.38)$ & 0.182 \\
\hline
\end{tabular}

Variable was included in multivariable model due to have $p$ value $<0.050$ in univariable analysis. OR, odds ratio; ORadj, adjusted odds ratio; CI, confident interval; BUN, blood urea nitrogen; Cr, creatinine; PD, peritoneal dialysis; EF, ejection fraction; NSTEMI, nonST-elevation myocardial infarction. ${ }^{1}$ Crude OR estimated by binary logistic regression. ${ }^{2} \mathrm{OR}_{\text {adj }}$ estimated by multiple logistic regressions.

Table 5. PD safety outcome

\begin{tabular}{|c|c|c|c|c|}
\hline Variables & Total $(n=147)$ & Dead $(n=108)$ & Alive $(n=39)$ & $p$ value* \\
\hline \multicolumn{5}{|l|}{ PD-related complication, $n(\%)$} \\
\hline PD peritonitis & $9(6.1)$ & $6(5.6)$ & $3(7.7)$ & 0.630 \\
\hline Malposition, need revision & $7(4.8)$ & $3(2.8)$ & $4(10.3)$ & 0.060 \\
\hline Malposition, without revision & $1(0.7)$ & $0(0.0)$ & $1(2.6)$ & 0.090 \\
\hline PD leakage & $10(6.8)$ & $7(6.4)$ & $3(7.6)$ & 0.790 \\
\hline PD technical failure (switch to IHD/CRRT), $n(\%)$ & $9(6.1)$ & $5(4.6)$ & $4(10.3)$ & 0.246 \\
\hline LOS, day, mean (SD) & $11(4-23)$ & $7(3-19)$ & $21(13-35)$ & $<0.001$ \\
\hline
\end{tabular}

Data are presented as $n(\%)$ or median (IQR). IHD, intermittent hemodialysis; CRRT, continuous renal replacement therapy; LOS, length of stay; PD, peritoneal dialysis; IQR, interquartile range; SD, standard deviation. * Comparison between death and survive groups; Mann-Whitney U test, $\chi^{2}$ test, and Fisher's exact test.

more effective where, in the long term, there was no plan for a left ventricular assist device or cardiac transplant. By contrast, PD is less costly than extracorporeal dialysis in AKI, including in CRS1. PD can be the efficient dialysis modality in selected cases of CRS1 (younger age and stable hemodynamic) to improve the outcome. PD allows for increased access to dialysis, especially in a resource-limited setting. However, the evidence for using PD in CRS is mainly in chronic heart failure (CRS type 2 ), not in CRS1 especially in critically ill cases. A Brazilian study reported the mortality rate was only $32.8 \%$ with high volume PD in CRS1 [19]. Nevertheless, the population in the Brazilian study was less severe in the etiology of CRS1 (only 50\% from ACS) and baseline status (only one-third required a vasoactive drug and mechanical ventilator) than our study. For the long-term renal out- come, our study reports the excellence rate of dialysis dependence at 90 days among the survival group was only $6.6 \%$. From this, we may conclude that critical CRS1 patients who required PD can survive and most had a renal recovery. Theoretically, extracorporeal dialysis causes more cardiac and hemodynamic disturbance than $\mathrm{PD}$, which one can postulate might be due to myocardial stunning during dialysis [23]. These advantages of PD may lead to quick renal recovery and a lower rate of dialysis dependence.

Another concern of using PD in CRS1 patients was PD complications. Our study reports $<15 \%$ for 2 common PD complications (PD peritonitis and $\mathrm{PD}$ catheter malfunction). Only $6 \%$ had PD technical failure, and their treatment was changed to extracorporeal dialysis. The complication rates of PD were in an acceptable 
range compared with studies of PD in septic AKI [2427]. Another advantage of PD in critically ill CRS1 patients is hemodynamic tolerability. In unstable hemodynamic CRS1 patients, there was a high risk of profound hypotension, arrhythmia, or even cardiac arrest during dialysis, especially in intermittent hemodialysis. This may lead the physician to delay the commencement of RRT or to terminate dialysis early. However, $\mathrm{PD}$ is well tolerated and so can be used in this critical CRS1 setting.

Fluid management, including UF from PD, was one of the interesting points in this study. First, PD can achieve an acceptable UF of up to 6-8 L in 5 PD sessions even in unstable hemodynamic CRS1 patients. Second, even though the accumulation of fluid before starting dialysis was not associated with the mortality in our study, when starting dialysis, negative total fluid balance and higher UF from PD at the first 5 dialysis sessions were associated with survival. This finding is consistent with another Brazilian study of PD in CRS1 patients [12]. The fluid overload consequent to tissue edema and may result in many organ dysfunctions from impaired oxygenation, distortion tissue architecture, obstruction capillary blood flow, and disturb cell-cell interaction [28]. Therefore, prescription high volume PD (up to $36 \mathrm{~L}$ ) and short duration $(1 \mathrm{~h})$ with high glucose $(4.25 \%)$ concentration of PD fluid to achieve high UF should be implemented in this situation to improve the outcome. The possibility of transient hyperglycemia from high PD fluid glucose concentration should be considered, but the benefit of negative fluid balance can be a trade-off for the risk of hyperglycemia.

To our knowledge, our study reports the largest study using PD in critical CRS1 patients with severe renal impairment. Our results show good tolerability, efficacy from UF to control fluid balance, and safety of $\mathrm{PD}$ in unstable hemodynamic CRS1 patients with a significant renal impairment that results mainly from acute myocardial infarction with cardiogenic shock. CRS1 has a wide spectrum in the severity of disease starting from mild cases with stable hemodynamics and normal renal function to critical cases with unstable hemodynamics and multi-organ failure. Many UF therapy studies have evaluated the fluid removal in CRS1 with mild renal insufficiency, but only a few studies have shown the tolerability of dialysis in critical CRS1 patients with severe AKI $[8,29]$. Moreover, there was only 1 study using PD for the specific case of CRS1 [19] which had a less critical population than this study. Our study fills the gap of knowledge for using PD support in critical CRS1 with multi-organ failure when CRRT is not available. Another point to consider is fluid balance in CRS1. There was already explicit evidence that positive fluid balance was associated with unfavorable outcomes in acute heart failure [30]. This study added the evidence that negative fluid balance with higher UF from PD can be associated with survival in CRS1 patients who require dialysis.

There are also some points to note about our study. First, this observational study did not compare with other methods of RRT. Therefore, it had selection bias due to severe unstable hemodynamic cases who might not tolerate extracorporeal dialysis and need RRT. Thus, our study has an emphasis on only CRS1 who perform PD. That is why the mortality of CRS1 patients in our study was high and it does not represent the overall mortality of CRS1 with AKI stage 3 patients.

Second, our data came from a single center that had well experience of using PD in various settings in AKI. The complications related to PD in AKI may be different for each center. Third, the fluid balances including urine output effect by a dose of diuretic which may vary depend on each clinician's judgment. Fourth, only one-third of critical CRS1 patients received IABP for organ support. The other mechanical methods of circulatory support, that is, tandem heart or left ventricular assist device were not available in our center.

Fluid removal is one of the key methods for improving the outcome in CRS1. UF by extracorporeal therapy is commonly applied in CRS1 patients without renal impairment to those with mild renal insufficiency, but the benefit in mortality is still inconclusive [31]. By contrast, the role of PD in CRS1 is interesting due to good hemodynamic tolerability and more cost-effectiveness in some low- to middle-income regions [32]. Further evidence of the role of PD in fluid removal or sodium removal is still needed. PD with low or sodium-free PD solutions or an adapted PD technique for removing mainly water and sodium in heart failure without AKI, then switching to high dextrose concentration PD solution for removal of both water and solute for significant renal impairment in CRS1 is a challenging idea. Further study is needed to evaluate the feasibility of this method.

The advantage of PD is hemodynamic tolerability and cost-effectiveness. Therefore, PD should be one of the attractive options for RRT in critical CRS1 patients in cardiogenic shock and in a limited-resource setting. Moreover, in young age with stable hemodynamic CRS1, performing PD to achieve negative cumulative fluid balance associated with improving survival. Set- 
ting up a PD program along with training for PD catheter insertion is a challenge for a center which has little experience with PD in AKI but is necessary for saving lives. At least, using PD in CRS1 can increase accessibility to dialysis when extracorporeal dialysis is unavailable or when there is hemodynamic intolerance. Such methods should help achieve the goal of the International Society of Nephrology of zero AKI-related preventable deaths by 2025 [33].

\section{Conclusion}

In a tertiary center setting, we found that CRS1 with AKI stage 3 from ACS who required PD had a high-mortality rate. Nevertheless, PD can save up to $27 \%$ of lives among severe CRS1 patients. PD can be an alternative dialysis modality to increase access to dialysis in critical CRS1.

\section{Acknowledgements}

I would like to thank all health-care staff, including resident of the department of medicine, Maharat. Nakhonratchasima Hospital for support PD in AKI.

\section{Statement of Ethics}

This study was approved by the Maharat Nakhorn Hospital Institution Review Board, with Approval number 065/2020. This is the retrospective data collection study, so the informed and consent were not performed.

\section{Conflict of Interest Statement}

All the authors declare that they have no conflicts of interest.

\section{Funding Sources}

This study did not require any funding.

\section{Author Contributions}

Watanyu Parapiboon and Tanit Kingjun participated in the data collection and wrote the manuscript. Watanyu Parapiboon participated in the study design and performed the statistical analysis. Watanyu Parapiboon and Tanit Kingjun participated in the conception, analysis, and interpretation of data. Laddaporn Wongluechai and Waraporn Leawnoraset provided intellectual content of critical importance to the work and technical support. Watanyu Parapiboon and Tanit Kingjun participated in the study design and coordination and helped to draft the manuscript. All the authors read and approved the final manuscript.

\section{References}

1 Ismail Y, Kasmikha Z, Green HL, McCullough PA. Cardio-renal syndrome type 1: epidemiology, pathophysiology, and treatment. Semin Nephrol. 2012 Jan;32(1):18-25.

2 Rangaswami J, Bhalla V, Blair JEA, Chang TI, Costa S, Lentine KL, et al. Cardiorenal syndrome: classification, pathophysiology, diagnosis, and treatment strategies: a scientific statement from the American heart association. Circulation. 2019;139(16):e840-78.

3 Pimienta González R, Couto Comba P, Rodríguez Esteban M, Alemán Sánchez JJ, Hernández Afonso J, Rodríguez Pérez MD, et al. Incidence, mortality and positive predictive value of type 1 cardiorenal syndrome in acute coronary syndrome. PLoS One. 2016;11(12):e0167166.

4 Roy AK, Mc Gorrian C, Treacy C, Kavanaugh E, Brennan A, Mahon NG, et al. A comparison of traditional and novel definitions (RIFLE, AKIN, and KDIGO) of acute kidney injury for the prediction of outcomes in acute decompensated heart failure. Cardiorenal Med. 2013 Apr;3(1):26-37.

5 Bart BA, Goldsmith SR, Lee KL, Givertz MM, O'Connor CM, Bull DA, et al. Ultrafiltration in decompensated heart failure with cardiorenal syndrome. N Engl J Med. 2012 Dec; 367(24):2296-304.
6 Costanzo MR, Guglin ME, Saltzberg MT, Jessup ML, Bart BA, Teerlink JR, et al. Ultrafiltration versus intravenous diuretics for patients hospitalized for acute decompensated heart failure. J Am Coll Cardiol. 2007 Feb; 49(6):675-83.

7 Costanzo MR, Negoianu D, Jaski BE, Bart BA, Heywood JT, Anand IS, et al. Aquapheresis versus intravenous diuretics and hospitalizations for heart failure. JACC Heart Fail. 2016 Feb;4(2):95-105.

8 Prins KW, Wille KM, Tallaj JA, Tolwani AJ. Assessing continuous renal replacement therapy as a rescue strategy in cardiorenal syndrome 1. Clin Kidney J. 2015 Feb;8(1): 87-92.

9 Premuzic V, Basic-Jukic N, Jelakovic B, Kes $P$. Continuous veno-venous hemofiltration improves survival of patients with congestive heart failure and cardiorenal syndrome compared to slow continuous ultrafiltration. Ther Apher Dial. 2017 Jun;21(3):27986.

10 Cullis B, Al-Hwiesh A, Kilonzo K, McCulloch $\mathrm{M}$, Niang A, Nourse P, et al. ISPD guidelines for peritoneal dialysis in acute kidney injury: 2020 update (adults). Perit Dial Int. 2020 Dec: 896860820970834 .
11 Burgner A, Ikizler TA, Dwyer JP. COVID-19 and the inpatient dialysis unit: managing resources during contingency planning pre-crisis. Clin J Am Soc Nephrol. 2020 May; 15(5): 720-2.

12 Puttagunta H, Holt SG. Peritoneal dialysis for heart failure. Perit Dial Int. 2015 Nov;35(6): 645-9.

13 Lu R, Muciño-Bermejo MJ, Ribeiro LC, Tonini E, Estremadoyro C, Samoni S, et al. Peritoneal dialysis in patients with refractory congestive heart failure: a systematic review. Cardiorenal Med. 2015 Apr;5(2):145-56.

14 Khalifeh N, Vychytil A, Hörl WH. The role of peritoneal dialysis in the management of treatment-resistant congestive heart failure: a European perspective. Kidney Int Suppl. 2006 Nov(103):S72-5.

15 Al-Hwiesh AK, Abdul-Rahman IS, Al-Audah $\mathrm{N}$, Al-Hwiesh A, Al-Harbi M, Taha A, et al. Tidal peritoneal dialysis versus ultrafiltration in type 1 cardiorenal syndrome: a prospective randomized study. Int J Artif Organs. 2019 Dec;42(12):684-94.

16 Chionh CY, Clementi A, Poh CB, Finkelstein FO, Cruz DN. The use of peritoneal dialysis in heart failure: a systematic review. Perit Dial Int. 2020 Nov;40(6):527-39. 
17 Khwaja A. KDIGO clinical practice guidelines for acute kidney injury. Nephron Clin Pract. 2012;120(4):c179-84.

18 Li PK, Szeto CC, Piraino B, de Arteaga J, Fan $S$, Figueiredo AE, et al. ISPD peritonitis recommendations: 2016 update on prevention and treatment. Perit Dial Int. 2016;36(5):481508.

19 Ponce D, Góes C, Oliveira M, Balbi A. Peritoneal dialysis for the treatment of cardiorenal syndrome type 1: a prospective brazilian study. Perit Dial Int. 2017 Oct;37(5):578-83.

20 Patarroyo M, Wehbe E, Hanna M, Taylor DO, Starling RC, Demirjian S, et al. Cardiorenal outcomes after slow continuous ultrafiltration therapy in refractory patients with advanced decompensated heart failure. J Am Coll Cardiol. 2012 Nov;60(19):1906-12.

21 Marenzi G, Cosentino N, Marinetti A, Leone AM, Milazzo V, Rubino M, et al. Renal replacement therapy in patients with acute myocardial infarction: rate of use, clinical predictors and relationship with in-hospital mortality. Int J Cardiol. 2017 Mar;230:25561.

22 van Diepen S, Tymchak W, Bohula EA, Park JG, Daniels LB, Phreaner N, et al. Incidence, underlying conditions, and outcomes of patients receiving acute renal replacement therapies in tertiary cardiac intensive care units: An analysis from the critical care cardiology trials network registry. Am Heart J. 2020;222: 8-14.
23 Zuidema MY, Dellsperger KC. Myocardial stunning with hemodialysis: clinical challenges of the cardiorenal patient. Cardiorenal Med. 2012 May;2(2):125-33.

24 Ponce D, Brito GA, Abrão JG, Balb AL. Different prescribed doses of high-volume peritoneal dialysis and outcome of patients with acute kidney injury. Adv Perit Dial. 2011;27: $118-24$.

25 Parapiboon W, Jamratpan T. Intensive versus minimal standard dosage for peritoneal dialysis in acute kidney injury: a randomized pilot study. Perit Dial Int. 2017 Sep;37(5):523-8.

26 Gabriel DP, Caramori JT, Martim LC, Barretti P, Balbi AL. High volume peritoneal dialysis vs daily hemodialysis: a randomized, controlled trial in patients with acute kidney injury. Kidney Int Suppl. 2008 Apr(108):S8793.

27 Al-Hwiesh A, Abdul-Rahman I, Finkelstein F, Divino-Filho J, Qutub H, Al-Audah N, et al. Acute kidney injury in critically ill patients: a prospective randomized study of tidal peritoneal dialysis versus continuous renal replacement therapy. Ther Apher Dial. 2018 Mar; 22(4):371.

28 Prowle JR, Echeverri JE, Ligabo EV, Ronco C, Bellomo R. Fluid balance and acute kidney injury. Nat Rev Nephrol. 2010 Feb;6(2):107-15.
29 Badawy SS, Fahmy A. Efficacy and cardiovascular tolerability of continuous veno-venous hemodiafiltration in acute decompensated heart failure: a randomized comparative study. J Crit Care. 2012 Feb;27(1):106-13.

30 Ambrosy AP, Cerbin LP, Armstrong PW Butler J, Coles A, DeVore AD, et al. Body weight change during and after hospitalization for acute heart failure: patient characteristics, markers of congestion, and outcomes: findings from the ASCEND-HF trial. JACC Heart Fail. 2017;5(1):1-13.

31 Barkoudah E, Kodali S, Okoroh J, Sethi R, Hulten E, Suemoto C, et al. Meta-analysis of ultrafiltration versus diuretics treatment option for overload volume reduction in patients with acute decompensated heart failure. Arq Bras Cardiol. 2015 May;104(5):41725.

32 Kilonzo KG, Akrabi HF, Yeates KE. Cost-effectiveness of acute peritoneal dialysis: considerations from Africa. Clin Nephrol. 2020 Jan;93(1):72-5.

33 Mehta RL, Cerdá J, Burdmann EA, Tonelli M, García-García G, Jha V, et al. International society of nephrology's 0 by 25 initiative for acute kidney injury (zero preventable deaths by 2025): a human rights case for nephrology. Lancet. 2015 Jun;385(9987):2616-43. 